\title{
COMPORTAMENTO FENOLÓGICO E EFEITO DA PODA EM ALGUMAS ESPÉCIES EMPREGADAS NA ARBORIZAÇÃO DO BAIRRO CAMOBI - SANTA MARIA, RS
}

Flávia Gisele König Brun ${ }^{1}$, Solon Jonas Longhi², Eleandro José Brun³ ${ }^{3}$ Ângela S. Freitag ${ }^{4}$, Mauro Valdir Schumacher ${ }^{5}$

\section{RESUMO}

Estudou-se a fenologia e influência da poda sobre 37 indivíduos (Lagerstroemia indica (08), Tabebuia chrysotricha (06), Eugenia uniflora (08), Caesalpinia peltophoroides (09) e Tipuana tipu (06)) da arborização de Santa Maria/RS, nas fenofases mudança foliar, floração e frutificação, durante 01 ano. Lagerstroemia indica apresentou desfolhamento durante 05 meses e brotação em 07, botões florais durante 06 e floração em 05. É sensível à poda, recomendando-se apenas podas leves. Tabebuia chrysotricha apresentou desfolhamento em 04 meses, brotação e folhas novas em 11 e velhas todo período, sendo fonte de inóculo da Crosta-marrom, recomendando-se poda dos ramos contaminados. A floração e frutificação apresentaram ciclo curto. A espécie aceita bem poda. Eugenia uniflora possui sua mudança foliar, floração e frutificação entre 10-12 meses, com sérias restrições à poda na frutificação. Para Caesalpinia peltophoroides, mudança foliar apresentou-se por 10-12 meses. Floração e frutificação apresentaram comportamento semelhante às de condições naturais. A poda não deve ser realizada na floração, pois reduz sua ocorrência. Na Tipuana tipu, o desfolhamento apresentou-se por 06 meses. As demais fenofases foliares ocorreram por 12. A floração apresentou-se em 02 meses, frutos novos em 05 e maduros em 03 . A poda participa como indutor foliar, floral e maturação dos frutos.

Palavras-chave: fenofases, condições climáticas, espécies arbóreas

\footnotetext{
1. Eng. Florestal, MSc. Acadêmica de Especialização em Educação Ambiental - CCR - UFSM. Santa Maria, RS. E-mail: flaviakonig@mail.ufsm.br.

2. Eng. Florestal, Prof. Dr. do Departamento de Ciências Florestais - CCR - UFSM. Santa Maria, RS. E-mail: solon.longhi@pesquisador.cnpq.br.

3. Eng. Florestal, M.Sc., Doutorando do PPGEF-UFSM. E-mail: eleandrojbrun@yahoo.com.br.

4. Eng. Florestal, Mestranda em Engenharia Agrícola - CCR - UFSM. Santa Maria, RS. E-mail: angela.floresta@hotmail.com.

5. Eng. Florestal, Prof. Dr. nat. techn do Departamento de Ciências Florestais - CCR - UFSM. Santa Maria, RS.

E-mail: schumacher@pesquisador.cnpq.br.
} 


\title{
FENOLOGICAL BEHAVIOR AND EFFECT OF THE PRUNING IN SOME USE SPECIES IN CAMOBI NEIGHBORHOOD URBAN TREES - SANTA MARIA, RS
}

\begin{abstract}
It was studied the fenology and influence of the pruning on 37 individuals (Lagerstroemia indica (08), Tabebuia chrysotricha (06), Eugenia uniflora (08), Caesalpinia peltophoroides (09) and Tipuana tipu (06)) of Santa Maria/RS's urban trees, in the phenophases leaves change, flowering and fruiting, for 01 year. Lagerstroemia indica it presented defoliating during 05 months and shooting in 07, floral buttons during 06 and flowering in 05 . It is sensitive to the pruning, being just recommended light prunings. Tabebuia chrysotricha presented defoliating in 04 months, shoots and new leaves in 11 and old leaves every period, being source of inoculum of the brown-crust, recommended prunes of the polluted branches. The flowering and fruiting presented short cycle. The species accepts well it prunes. Eugenia uniflora present your foliar change, flowering and fruiting among 10-12 months, with serious restrictions to the pruning in the fruiting. To Caesalpinia peltophoroides, the foliar change occurs for 10-12 months. Flowering and fruiting presented behavior similar to the natural conditions. The pruning should not be accomplished in the flowering, because it reduces your occurrence. In the Tipuana tipu, the defoliating occurs for 06 months. The other foliar fenofases occurs for 12. The flowering occurs in 02 months, new fruits in 05 and ripe in 03 . The pruning participates as inductor to new leaves, flowering and maturation of the fruits.
\end{abstract}

Key-words: fenofases, climatic conditions, tree species. 


\section{INTRODUÇÃO}

A fenologia é o estudo dos aspectos biológicos que se sucedem no desenvolvimento de uma espécie, acomodados dentro de certo ritmo periódico como brotação, floração e maturação dos frutos (Longhi, 1984).

$\mathrm{Na}$ arborização urbana, o conhecimento fenológico das espécies vegetais componentes, que sempre vivem sob algum nível de estresse fisiológico, pode indicar, de acordo com o seu ritmo de fenofases em situação natural, a presença ou ausência de regularidade no mesmo e, neste último caso, ser base para o planejamento de ações silviculturais que permitam uma melhor adaptação das espécies ao ambiente urbano.

Marchiori (1995) salienta que, no paisagismo, informações fenológicas como limites e extensão do período da caducidade foliar e delimitação do período de floração ou frutificação, constituem na base para o planejamento da arborização urbana, para que se efetue a modelagem plástica da vegetação, uma vez que isso requer necessariamente um conhecimento minuncioso dos ritmos biológicos das espécies vegetais, para lograr boas composições estéticas.

Segundo Velasco (2003), a poda é utilizada para adequar a planta ao interesse do homem que habita a cidade, sendo, desta forma, executada para corrigir os conflitos existentes entre as árvores e os equipamentos e/ou edificações da cidade. O autor afirma que a poda é uma agressão a um organismo vivo, com estruturas e funções definidas e alguns mecanismos de defesa contra seus inimigos naturais. Sendo assim, a prática da poda não deve ser totalmente abolida, mas sim, se usada de forma correta evita que grandes erros sejam cometidos na ilusão de estar realizando o melhor para as plantas, pois favorece-se a entrada de patógenos pelos ferimentos que a poda causa.

Porém, nem sempre a prática da poda é utilizada de forma correta, como relatado anteriormente, como é no caso da arborização urbana da Vila Santos Dumont, Bairro Camobi, Santa Maria, onde König et al. (2003a) realizaram um levantamento sobre danos mecânicos na arborização urbana e verificaram que 5,3\% dos indivíduos da arborização urbana sofreram danos por realização de poda sem orientação, onde as principais espécies injuriadas foram Pinus sp. (Pinus), Lagerstroemia indica (Extremosa) e Tabebuia chrysotricha (Ipê-amarelo).

Dentro deste contexto, o presente estudo teve por objetivo avaliar o comportamento fenológico e a influência das interferências antrópicas, como a poda, sobre a fenologia de algumas espécies arbóreas (Extremosa (Lagerstroemia indica), Ipê-amarelo (Tabebuia chrysotricha), Pitangueira (Eugenia uniflora), Sibipiruna (Caesalpinia peltophoroides) e Tipuana (Tipuana tipu)) empregadas na arborização urbana da Vila Santos Dumont, Bairro Camobi, Santa Maria, RS. 


\section{MATERIAL E MÉTODOS}

\section{Descrição da área de Estudo}

O presente estudo foi realizado na Vila Santos Dumont, situada no Bairro Camobi, município de Santa Maria, RS, nas coordenadas geográficas de 29²4'18" de latitude Sul e 534'ㄱ' habitantes, numa área total de $66.580 \mathrm{~m}^{2}$. A vila apresenta uma arborização composta por 584 indivíduos arbóreos (König et al., 2003b), em composta por 10 vias públicas, que podem ser observadas na Figura 1.

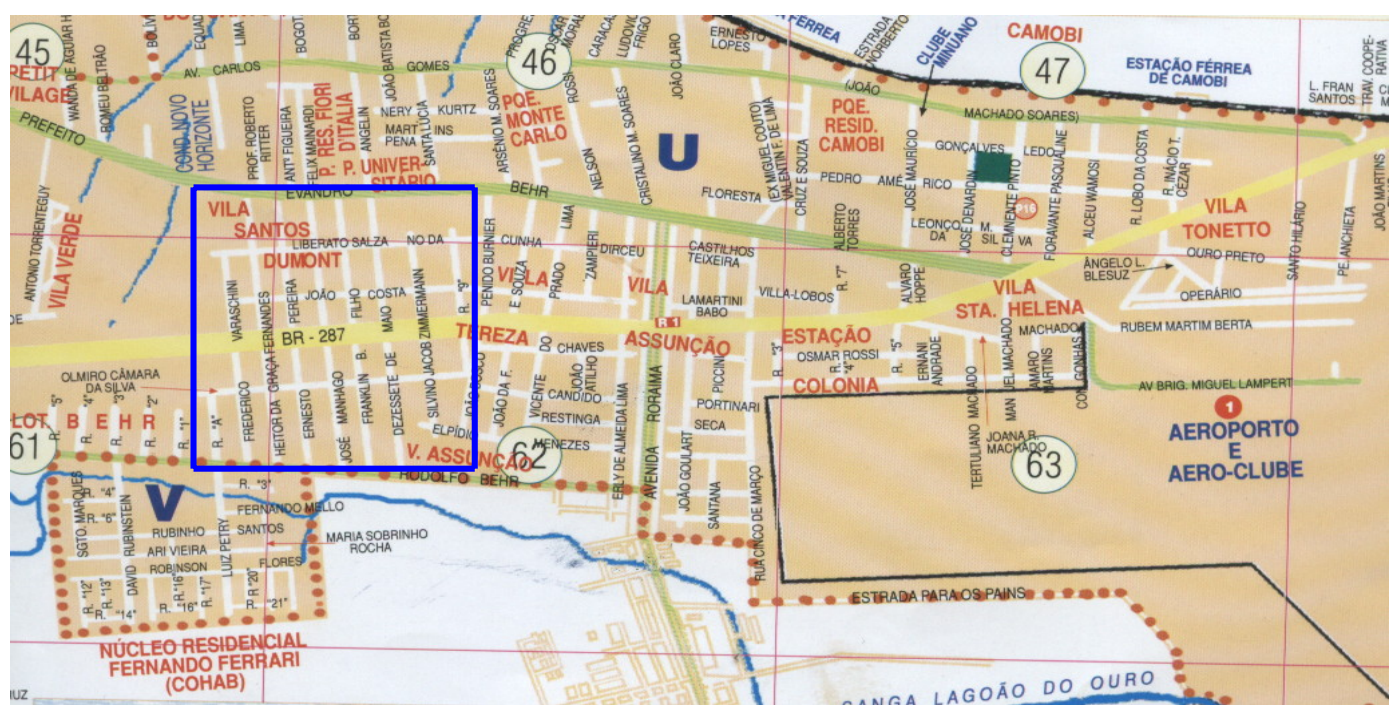

Figura 1: Área de Estudo (encontra-se destacada em azul). Fonte: Prefeitura Municipal de Santa Maria (2002).

O clima da região é o subtropical temperado, do tipo "Cfa 2", segundo a classificação de Köppen (Moreno, 1961), caracterizada por temperatura média anual entre 17,9 e 19,2 ${ }^{\circ} \mathrm{C}$ sendo que a temperatura média do mês mais quente é superior a $22^{\circ} \mathrm{C}$. As chuvas são bem distribuídas ao longo do ano, sendo que a precipitação média anual fica em torno de 1400 e $1760 \mathrm{~mm}$. Sendo que as variáveis climáticas durante o período observado apresentaram o seguinte comportamento, conforme descrito na Tabela 1. 
Tabela 1: Variáveis climáticas observadas durante o período de estudo.

\begin{tabular}{lccccc}
\hline \multicolumn{1}{c}{ Mês/ano } & $\begin{array}{c}\text { Precipitação } \\
(\mathbf{m m})\end{array}$ & Insolação (h) & $\begin{array}{c}\text { Temp. Média } \\
\left({ }^{\circ} \mathbf{C}\right)\end{array}$ & $\begin{array}{c}\text { Temp. } \\
\text { Máx }\left({ }^{\circ} \mathbf{C}\right)\end{array}$ & $\begin{array}{c}\text { Temp. } \\
\text { Min. }\left({ }^{\circ} \mathbf{C}\right)\end{array}$ \\
\hline Outubro/03 & 193,4 & 6,6 & 21,4 & 26,9 & 14,9 \\
Novembro/03 & 228,6 & 7,3 & 23,0 & 28,0 & 16,6 \\
Dezembro/03 & $\mathbf{4 2 3 , 9 ^ { * }}$ & 7,7 & 23,2 & 27,6 & 17,3 \\
Janeiro/04 & $\mathbf{2 1 , 7}$ & 8,8 & $\mathbf{2 6 , 6}$ & $\mathbf{3 1 , 7}$ & $\mathbf{1 9 , 8}$ \\
Fevereiro/04 & 110,8 & $\mathbf{9 , 1}$ & 24,9 & 29,7 & 18,1 \\
Março/04 & 86,0 & 7,2 & 24,5 & 30,1 & 17,3 \\
Abril/04 & 101,5 & 6,0 & 22,6 & 28,1 & 16,4 \\
Maio/04 & 80,5 & $\mathbf{4 , 4}$ & 15,5 & 19,6 & 11,6 \\
Junho/04 & 72,6 & 4,6 & 16,7 & 21,6 & 11,7 \\
Julho/04 & 72,5 & 5,5 & $\mathbf{1 4 , 4}$ & $\mathbf{1 9 , 5}$ & $\mathbf{8 , 8}$ \\
Agosto/04 & 93,3 & 5,3 & 16,6 & 22,0 & 11,2 \\
Setembro/04 & 96,3 & $\mathbf{4 , 4}$ & 19,4 & 24,4 & 13,8 \\
\hline
\end{tabular}

Fonte: Estação Meteorológica da UFSM. *Os valores grifados representam os extremos de variação.

O solo classifica-se como pertencente às Unidades de Mapeamento São Pedro e Santa Maria, sendo que os mesmos denominam-se respectivamente como: Argissolo Vermelho distrófico típico de textura média com relevo ondulado e substrato arenítico e Alissolo Hipocrômico argilúvico típico, textura média, de relevo plano a levemente ondulado e substrato siltito-arenito (Streck et al., 2002).

\section{Metodologia específica}

Para o presente estudo, foi avaliado um total de 37 árvores nas vias públicas da Vila Santos Dumont, sendo: Extremosa (Lagerstroemia indica) com 08 indivíduos, Ipê-amarelo (Tabebuia chrysotricha) com 06 indivíduos, Pitangueira (Eugenia uniflora) com 08 indivíduos, Sibipiruna (Caesalpinia peltophoroides) com 09 indivíduos e Tipuana (Tipuana tipu) com 06 indivíduos.

Os dados foram coletados conforme a metodologia proposta por Longhi (1984), onde foram abrangidas as fenofases de floração, frutificação e mudança foliar, sendo que cada uma destas foi caracterizada da seguinte forma: Mudança foliar (Árvore desfolhadas, Brotação, Folhas novas e Folhas velhas), Floração (Botões florais, Floração adiantada ou árvore totalmente florida, Floração terminada ou terminando) e Frutificação (Frutos novos, Frutos maduros e Frutos caindo ou sementes dispersas). A coleta de dados ocorreu através da observação in loco nas vias públicas, visualizando-se as condições dos indivíduos arbóreos previamente identificados no local, por meio de uma pequena marcação com tinta spray na base do tronco. A coleta foi realizada com uma periodicidade quinzenal, tendo iniciado na segunda quinzena do mês de Outubro de 2003, indo até a segunda quinzena do mês de Setembro de 2004.

Além da avaliação de ocorrência das fenofases, observou-se a influencia do fator antrópico poda no comportamento fenológico das espécies avaliadas, sendo que para esta 
avaliação, foram anotadas na planilha de coleta de dados, a ocorrência dos eventos nos indivíduos e, posteriormente, foram realizadas as correlações com as fenofases para que fosse estabelecida sua influência sobre as mesmas.

\section{Processamento dos dados}

Para o processamento dos dados coletados na área de estudos, empregou-se o software Microsoft Excel, onde se elaborou uma planilha com dados quinzenais para o estabelecimento das médias mensais da intensidade de ocorrência das fenofases.

Para a avaliação da influência do efeito da poda sobre cada fenofase, foram estabelecidas as correlações de Pearson, as quais foram realizadas através da planilha eletrônica Microsoft Excel. Para estas avaliações, foram consideradas correlações significativas, valores acima de $(r=+/-0,30)$, sendo " $r$ " baixo, os valores situados entre $r=$ 0,30 e 0,40 (tanto positivo quanto negativo) e " $r$ " alto, os valores acima de $r=0,40$ (tanto positivo quanto negativo).

\section{RESULTADOS E DISCUSSÃO}

\section{Comportamento Fenológico das Espécies}

\section{Extremosa (Lagerstroemia indica)}

A Tabela 2 apresenta o comportamento fenológico da Extremosa, quanto aos indivíduos estudados na Vila Santos Dumont.

Tabela 2: Período de ocorrência das fenofases da Extremosa, na arborização da Vila Santos Dumont - Bairro Camobi, Santa Maria - RS (2003 - 2004).

\begin{tabular}{|c|c|c|c|}
\hline Fenofase & Período & Duração & Pico \\
\hline \multicolumn{4}{|c|}{ Mudança Foliar } \\
\hline Árvore desfolhada & Maio a Setembro & 05 meses & Agosto \\
\hline Brotação & Agosto a Março & 07 meses & Setembro \\
\hline Folhas novas & Agosto a Abril & 10 meses & Novembro a Dezembro \\
\hline Folhas velhas & Agosto (2003) a Junho (2004) & 10 meses & $\begin{array}{l}\text { Novembro a Dezembro I } \\
\text { Fevereiro a Março }\end{array}$ \\
\hline \multicolumn{4}{|c|}{ Floração } \\
\hline Botões Florais & Novembro a Abril /Setembro & 06 meses & Dezembro \\
\hline Floração adiantada & Dezembro a Abril/Setembro & 05 meses & Fevereiro \\
\hline Floração terminada & Março a Abril & 02 meses & Abril \\
\hline \multicolumn{4}{|c|}{ Frutificação } \\
\hline Frutos novos & Janeiro a Maio & 05 meses & Fevereiro a Março \\
\hline Frutos maduros & Fevereiro a Junho /Agosto & 06 meses & Março \\
\hline Frutos caindo & Março a Junho & 04 meses & Maio \\
\hline
\end{tabular}

Para mudança foliar, os maiores índices de folhas velhas ocorrem nos meses de novembro de 2003 a maio de 2004, quando, a partir deste mês, a espécie passou a perder 
suas folhas, atingindo a época de maior perda em julho do corrente ano. A época em que ocorreu o desfolhamento natural na espécie foi entre os meses de maio a julho de 2004.

As brotações, nesta espécie, têm início em agosto de 2003, atingindo seu ápice em setembro de 2004.

A floração, para a extremosa, é encontrada nos meses de dezembro a abril, sendo a emissão de botões florais o período mais longo, com seis meses de duração. O ápice da emissão de botões florais ocorre no mês de dezembro de 2003. Já, a maior intensidade de floração adiantada ocorre no mês de fevereiro de 2004. A fase terminal de floração da extremosa iniciou no mês de fevereiro, atingindo o máximo em abril.

Já a frutificação é verificada entre os meses de fevereiro a maio de 2004 , sendo a fenofase de frutos maduros, a mais longa com seis meses de duração (fevereiro a agosto). Quanto à queda de frutos, ocorreu nos meses de Março a Junho.

\section{Ipê-amarelo (Tabebuia chrisotrycha)}

Para Ipê-amarelo, a mudança foliar quanto à brotação e folhas novas apresentou um ciclo de onze meses (Tabela 3), enquanto que a presença de folhas velhas e árvore desfolhada duraram em torno de sete a doze meses. A ocorrência de árvore desfolhada para o Ipê-amarelo foi observada nos meses de junho a outubro e também de dezembro a janeiro, sendo este último período relatado devido às podas realizadas pelos moradores da Vila, portanto, o período normal desta ocorrer é o primeiro relatado. Longhi (1984) estudando a fenologia de algumas espécies ornamentais do Campus da UFSM, em Santa Maria, RS, observou que o período de desfolhamento para esta espécie era de Agosto a Outubro, e Lorenzi (1998), coloca que em habitat natural esta fenofase ocorre de Agosto a Setembro.

Tabela 3: Período de ocorrência das fenofases do Ipê-amarelo, na arborização da Vila Santos Dumont - Bairro Camobi, Santa Maria - RS. (2003 - 2004).

\begin{tabular}{|c|c|c|c|}
\hline Fenofase & Período & Duração & Pico \\
\hline \multicolumn{4}{|c|}{ Mudança Foliar } \\
\hline Árvore desfolhada & Dezembro a Janeiro/ Junho a Setembro & 07 meses & Agosto \\
\hline Brotação & Outubro a Abril/ Junho a Setembro & 11 meses & Outubro/Agosto \\
\hline Folhas novas & Outubro a Julho/ Setembro & 11 meses & Dezembro \\
\hline Folhas velhas & Outubro a Setembro & 12 meses & Novembro a Março \\
\hline \multicolumn{4}{|c|}{ Floração } \\
\hline Botões Florais & Julho a Outubro & 04 meses & Julho a Agosto \\
\hline Floração adiantada & Julho a Outubro & 04 meses & Agosto \\
\hline Floração Terminada & Julho a Outubro & 04 meses & Agosto \\
\hline \multicolumn{4}{|c|}{ Frutificação } \\
\hline Frutos novos & Agosto a Novembro & 03 meses & Setembro \\
\hline Frutos maduros & Setembro a Outubro & 02 meses & Outubro \\
\hline Frutos caindo & Outubro a Dezembro & 03 meses & Novembro \\
\hline
\end{tabular}


O fato de terem sido encontradas folhas velhas durante todo o período de avaliação se deve a não ocorrência da caducifolia completa dos indivíduos observados como característico da espécie, um inconveniente da não ocorrência desta é a disseminação, reinfecção e ataque severos de patógenos como Apiosphaeria guaranitica, causador da crosta-marrom do Ipê, doença comum dos indivíduos empregados na arborização urbana, que pode ocasionar abscisão prematura das folhas e redução na taxa de sintetização de carboidratos pela planta.

A brotação ocorreu durante um período de onze meses na espécie. O único mês que não foi verificada esta foi em maio, tal fato se deve ao curto período de insolação diária, apenas 4,4 horas ao dia, o que pode ter inibido a ação dos hormônios responsáveis pela formação de tecidos foliares e conseqüentemente inibindo totalmente a formação dos brotos neste período, sendo este fator responsável pela baixa intensidade de folhas novas nos meses subseqüentes, mas embora a presença das mesmas observadas durante todo período, assim como as folhas velhas.

A floração possui, em todas as suas fases (botões florais, floração adiantada e floração terminada), um ciclo de quatro meses, enquanto que a frutificação ocorre em um período de 2 a 3 meses, no período de junho a outubro, destacando-se uma elevada formação de botões florais nos meses de junho e julho. Longhi (1984) observou para indivíduos da espécie no Campus da UFSM, a floração ocorrendo dos meses de junho a setembro, ou seja, um mês a menos ao observado no presente estudo.

Carvalho (1976), estudando o comportamento fenológico da espécie nos plantios da Estação Experimental de Saltinho, PE, relatou a ocorrência da floração na espécie nos meses de outubro a fevereiro, o aumento do período de floração relatado pelo autor citado acima em relação a este estudo se deve pela elevação das temperaturas, pois a área estudada pelo autor se encontra em uma localização de clima tropical, que propicia fotoperíodos maiores, que são fatores preponderantes para um maior e mais intenso período de florada.

Quanto à frutificação, verificou-se que a emissão de frutos novos iniciou-se em agosto, porém com pouca intensidade, e tendo seu pico em setembro, e sendo retomada em novembro, pois em outubro foi nula.

A maturação dos frutos ocorreu no período de setembro a outubro, sendo que o período mais indicado para coleta de sementes viáveis se dá no mês de outubro, por ser o pico desta fenofase. A queda dos frutos se concentrou nos meses de outubro a dezembro, portanto a frutificação do Ipê-amarelo apresenta-se de agosto a dezembro, neste estudo, pois Longhi (1984), para os exemplares do Campus da UFSM, relatou a ocorrência da frutificação nos meses de agosto a novembro. 


\section{Pitangueira (Eugenia uniflora)}

As fenofases de mudança foliar, floração e frutificação da pitangueira são uma das mais longas, sendo encontrados frutos maduros durante todo o período de coleta de dados (12 meses) e a presença de botões florais durante dez meses. Além disso, durante todo o período foram encontradas também folhas novas e velhas (Tabela 4).

A emissão de brotação iniciou em novembro de 2003 e, com maior ou menor intensidade, sempre foi verificada nesta espécie. Houve alguns períodos onde a emissão de brotação foi mais intensa, como por exemplo, no período que vai de abril a junho, atingindo o auge em maio, sendo que em setembro de 2004, novamente foi verificado aumento na intensidade de brotação.

Tabela 4: Período de ocorrência das fenofases da Pitangueira, na arborização da Vila Santos Dumont - Bairro Camobi, Santa Maria - RS. (2003 - 2004).

\begin{tabular}{|c|c|c|c|}
\hline Fenofase & Período & Duração & Pico \\
\hline \multicolumn{4}{|c|}{ Mudança Foliar } \\
\hline Brotação & Novembro a Setembro & 10 meses & Setembro \\
\hline Folhas novas & Outubro a Setembro & 12 meses & Novembro a Dezembro / Maio \\
\hline Folhas velhas & Outubro a Setembro & 12 meses & Fevereiro \\
\hline \multicolumn{4}{|c|}{ Floração } \\
\hline Botões Florais & Dezembro a Setembro & 10 meses & Setembro \\
\hline Floração adiantada & Dezembro a Setembro & 10 meses & Setembro \\
\hline Floração Terminada & Outubro/Agosto e Setembro & 03 meses & Setembro \\
\hline \multicolumn{4}{|c|}{ Frutificação } \\
\hline Frutos novos & Outubro a Abril /Setembro & 07 meses & Novembro \\
\hline Frutos maduros & Outubro a Setembro & 12 meses & Novembro \\
\hline Frutos caindo & Outubro a Janeiro/Março & 05 meses & Novembro \\
\hline
\end{tabular}

A presença de folhas velhas se manteve quase que inalterada, mantendo quase que a mesma intensidade durante todo o período, enquanto que a intensidade de folhas novas diminuiu em fevereiro, devido às baixas precipitações ocorridas no mês de janeiro de 2004, conforme a Tabela 1. No entanto, observaram-se algumas quedas das folhas novas e velhas, durante os meses de julho. Em setembro houve novamente aumento na intensidade de folhas novas. Isso reafirma que a espécie em questão possui foliação perene quando em seu habitat natural, conforme o relato de Marchiori \& Sobral (1997), assim como em condições urbanas, conforme avaliado neste trabalho.

A espécie em questão apresenta intensidades de botões florais de forma muito diversificadas, pode-se observar que o início da emissão de botões florais ocorre no mês de dezembro de 2003 até o mês de setembro de 2004.

A presença de floração adiantada foi verificada no mês de dezembro de 2003 , enquanto que a floração em estágio terminal só foi presenciada nos meses de outubro e novembro de 2003, com intensidades cada vez menores. 
Estes valores encontrados no presente trabalho condizem muito com os valores encontrados para a espécie em mata nativa (habitat natural) por Marchiori \& Sobral (1997) que afirmam que a época de maior intensidade de floração é observada nos meses de agosto a setembro, aparecendo juntamente com a emissão de brotos e folhas novas. A partir disso pode-se concluir que a espécie se adaptou bem ao ambiente urbano, sendo indicada para arborização sem que sua fenofase sofra com as advertências impostas pelo meio.

Na frutificação da pitangueira em ambiente urbano, verifica-se que em setembro deuse início a emissão de frutos novos, maduros e frutos caindo. As três fases de frutificação avaliadas ocorreram de forma concomitante, com maior presença de ambas as fenofases em novembro de 2003. A partir deste mês, a intensidade de ambas as três fenofases começou a cair até o mês de janeiro onde começaram a apresentar comportamento diferenciado. A presença de frutos caindo se tornou cada vez menor até o momento em que não houve mais frutificação caindo enquanto que a presença de frutos novos começou a variar com picos de queda no mês de março e nos meses de junho a agosto. Em agosto, ocorreu uma segunda florada, onde foi verificado o aumento de frutos novos e em setembro constatamos a maior quantidade de frutos novos. Estes dados vão ao encontro dos resultados encontrados por Marchiori \& Sobral (1997), que afirmam que as variações climáticas costumam intervir na fenologia, produzindo duas ou mais florações anuais, das quais a mais intensa verifica-se no reinicio da atividade vegetativa, em agosto e setembro, aparecendo juntamente com a emissão de brotos e folhas novas. Quanto à presença de frutos maduros verificou-se que estes também sempre estiveram presentes, porém com maiores variações de intensidade.

\section{Sibipiruna (Caesalpinia peltophoroides)}

As mudanças foliares para sibipiruna tiveram comportamento igual ao comportamento da pitangueira, com um ciclo de 10 a 12 meses para as três fenofases avaliadas (Tabela 5).

Ao avaliarmos o comportamento fenológico da sibipiruna, constatamos que a espécie não apresenta perda de folhas nos exemplares, com exceção dos meses de agosto e setembro, onde a intensidade observada foi mínima pois, segundo Marchiori (1997), a espécie é caracterizada como semidecídua, portanto, assim como a pitangueira, ela perde suas folhas ao longo do ano, de forma contínua e em pequenas intensidades. A presença de árvore desfolhada no mês de setembro é mais uma vez devido à ocorrência de podas feitas pelos moradores. Quanto à emissão de brotação, este estágio se comporta de forma muito variada. As maiores presenças de brotação foram encontradas nos meses de dezembro de 2003 e março de 2004. Nos meses de abril a setembro também foi constatada a presença 
de brotações, porém em menor intensidade. Já nos meses de janeiro e fevereiro não houve brotação devido ao fato de em janeiro a precipitação pluviométrica ter sido muito baixa $(21,7$ $\mathrm{mm}$ ) (Tabela 1).

Tabela 5: Período de ocorrência das fenofases da Sibipiruna, na arborização da Vila Santos Dumont - Bairro Camobi, Santa Maria - RS (2003 - 2004).

\begin{tabular}{|c|c|c|c|}
\hline Fenofase & Período & Duração & Pico \\
\hline \multicolumn{4}{|c|}{ Mudança Foliar } \\
\hline Brotação & $\begin{array}{l}\text { Outubro a Dezembro/ Março a } \\
\text { Setembro }\end{array}$ & 10 meses & Dezembro \\
\hline Folhas novas & Outubro a Setembro & 12 meses & $\begin{array}{l}\text { Novembro /Janeiro a } \\
\text { Fevereiro }\end{array}$ \\
\hline Folhas velhas & Outubro a Setembro & 12 meses & Outubro a Maio/Julho \\
\hline \multicolumn{4}{|c|}{ Floração } \\
\hline Botões Florais & Agosto a Outubro/ Dezembro & 04 meses & Outubro \\
\hline Floração adiantada & Outubro a Novembro & 02 meses & Outubro \\
\hline Floração Terminada & Outubro a Novembro & 02 meses & Novembro \\
\hline \multicolumn{4}{|c|}{ Frutificação } \\
\hline Frutos novos & Outubro a Setembro & 12 meses & $\begin{array}{l}\text { Novembro a Dezembro/ } \\
\text { Fevereiro a Março/Maio }\end{array}$ \\
\hline Frutos maduros & Outubro/Março a Setembro & 08 meses & Setembro \\
\hline Frutos caindo & Junho a Julho/Setembro & 03 meses & Junho a Julho/Setembro \\
\hline
\end{tabular}

A intensidade de folhas velhas teve comportamento linear entre os meses de outubro de 2003 a maio de 2004, com valores máximos. Em junho observou-se uma queda na quantidade de folhas velhas, o que se acentuou no mês de setembro. A presença de folhas novas também foi significativa, mas não de forma tão linear quanto ao observado para folhas velhas. No mês de maio começaram a ser verificadas quedas na quantidade de folhas novas. Este fato se estendeu até o mês de setembro.

Quanto à floração, constatou-se que ela se fez presente durante os meses de outubro e novembro. Em outubro de 2003 encontramos a maior intensidade de botões florais e em novembro, já não existiam mais, ressurgindo em dezembro de 2003. A emissão de botões florais teve seu reinicio novamente no mês de julho até mês de setembro, final das avaliações do presente estudo. Na floração adiantada também observamos que a maior intensidade ocorreu no mês de outubro.

A floração terminada foi observada no mês de outubro e novembro. Segundo Marchiori (1997), a floração desta espécie, em ambiente natural, foi verificada entre os meses de agosto e novembro, fato que se pode considerar também em ambiente urbano.

A presença significativa de frutos novos ocorreu durante os doze meses de avaliação, a presença de frutos maduros ocorreu no mês de outubro de 2003 e durante os meses de março a setembro, no qual o pico foi constatado no mês de setembro, sendo está, a época mais adequada para a coleta de sementes nos indivíduos desta espécie. 
A presença de frutos caindo se assemelha muito com o comportamento das folhas caindo. Os frutos maduros se apresentaram com maior intensidade no mês de setembro, época me que encontramos a menor quantidade de folhas velhas.

Nesta espécie, também houve uma aproximação da fenofase de maturação dos frutos no habitat natural e em ambientes urbanos, o qual é verificado entre os meses de julho a setembro em ambos os casos.

\section{Tipuana (Tipuana tipu)}

A presença da fenofase árvore desfolhada para a tipuana em ambiente natural ocorre apenas nos meses do outono e inverno. Constata-se, segundo os dados do presente trabalho, que em ambiente urbano esta fenofase ocorreu principalmente no verão, devido às podas realizadas visando correção de copas em função da ocorrência de um vendaval neste período, e também no inverno (Tabela 6).

Para as demais fenofases ligadas à mudança foliar, estas se apresentaram durante todo o período de coleta de dados (doze meses).

Tabela 6: Período de ocorrência das fenofases da Sibipiruna, na arborização da Vila Santos Dumont - Bairro Camobi, Santa Maria - RS (2003 - 2004).

\begin{tabular}{|c|c|c|c|}
\hline Fenofase & Período & Duração & Pico \\
\hline \multicolumn{4}{|c|}{ Mudança Foliar } \\
\hline Árvore desfolhada & $\begin{array}{l}\text { Outubro/Dezembro a Janeiro/Junho a } \\
\text { Agosto }\end{array}$ & 06 meses & $\begin{array}{l}\text { Outubro/Dezembro a } \\
\text { Janeiro/Junho a Julho }\end{array}$ \\
\hline Brotação & Outubro a Setembro & 12 meses & Outubro \\
\hline Folhas novas & Outubro a Setembro & 12 meses & $\begin{array}{l}\text { Novembro a Fevereiro/ } \\
\text { Abril }\end{array}$ \\
\hline Folhas velhas & Outubro a Setembro & 12 meses & Novembro a Maio \\
\hline \multicolumn{4}{|c|}{ Floração } \\
\hline Botões Florais & Novembro a Dezembro & 02 meses & Novembro \\
\hline $\begin{array}{l}\text { Floração } \\
\text { adiantada }\end{array}$ & Novembro a Dezembro & 02 meses & Novembro \\
\hline $\begin{array}{l}\text { Floração } \\
\text { terminada }\end{array}$ & Dezembro & 01 mês & Dezembro \\
\hline \multicolumn{4}{|c|}{ Frutificação } \\
\hline Frutos novos & Dezembro a Junho/Agosto & 08 meses & Fevereiro \\
\hline Frutos maduros & Março a Setembro & 07 meses & Abril a Junho \\
\hline Frutos caindo & Abril a Julho & 04 meses & Abril/Junho \\
\hline
\end{tabular}

A emissão de botões florais e floração adiantada foram verificadas apenas nos meses de novembro e dezembro, tendo para ambos, o pico em novembro. A floração terminada foi verificada apenas no mês de dezembro. A fenofase de frutificação foi verificada durante os meses de dezembro de 2003 a setembro de 2004, sendo que a presença de frutos novos teve duração de oito meses, tendo maior pico em fevereiro e a presença de frutos maduros teve duração de sete meses, tendo seu pico de abril a junho. $A$ 
presença de frutos caindo foi verificada durante quatro meses e o pico de maior queda de frutos maduros ocorreu entre abril e junho.

\section{Efeito da Poda no Comportamento Fenológico das Espécies Estudadas}

$\mathrm{Na}$ Tabela 7, apresenta-se o efeito da poda no comportamento fenológico das espécies estudadas na Vila Santos Dumont, Bairro Camobi, através de análise estatística por meio da Correlação de Pearson (r), com nível de significância de 95\%.

As espécies que mais sofreram os efeitos da poda em seu ciclo fenológico foram a Extremosa (Lagerstroemia indica) e a Tipuana (Tipuana tipu), sendo que a primeira espécie citada, em maior intensidade, de forma negativa em quase todas as suas fenofases: folhas velhas $(r=-0,72)$, folhas novas $(r=-0,42)$, botões florais $(r=-0,52)$, floração adiantada ( $r=-$ $0,57)$, floração terminada $(r=-0,35)$ e também na formação de frutos novos $(r=-0,57)$ e maduros $(r=-0,36)$, o que demonstra susceptibilidade da espécie a estresses fisiológicos oriundos da prática da poda, tornando as árvores extremamente vulneráveis ao ataque de fungos, como Oidium sp., que no ano de 2004, consagrou-se como uma verdadeira epidemia na arborização da Vila Santos Dumont, provocando seus danos mais severos em indivíduos podados.

Tabela 7: Efeito da poda no comportamento fenológico das espécies estudadas na Vila Santos Dumont, Bairro Camobi, Santa Maria, RS. (2003 - 2004), através de análise estatística por meio da Correlação de Pearson (r).

\begin{tabular}{ccc}
\hline Espécie & $\mathbf{r}$ & Fenofase \\
\hline \multirow{2}{*}{ Lagerstroemia indica } & $\mathbf{0 , 7 8}$ & \\
& $-\mathbf{0 , 7 2}$ & Árv. desfolhada \\
& $\mathbf{0 , 6 7}$ & Folhas velhas \\
\hline \multirow{2}{*}{ Tabebuia chrisotrycha } & $-\mathbf{0 , 7 1}$ & Árv. desfolhada \\
& $-\mathbf{0 , 4 2}$ & Folhas novas \\
\hline Eugenia uniflora & $-\mathbf{0 , 4 0}$ & Folhas velhas \\
\hline Caesalpinia peltophoroides & $-\mathbf{0 , 3 2}$ & Folhas novas \\
\hline Tipuana tipu & $-\mathbf{0 , 4 2}$ & Folhas novas \\
\hline & $\mathbf{F l o r a c ̧ a ̃ o ~}$ & Folhas novas \\
\hline \multirow{2}{*}{ Lagerstroemia indica } & $-\mathbf{0 , 5 2}$ & \\
\hline \multirow{2}{*}{ Tabebuia chrisotrycha } & $-\mathbf{0 , 5 7}$ & Botões florais \\
& $\mathbf{- 0 , 3 5}$ & Flor. adiantada \\
& $\mathbf{0 , 5 9}$ & Fotor. terminada \\
\hline & $\mathbf{0 , 7 2}$ & Flor. adiantada \\
& $\mathbf{0 , 5 2}$ & Flor. terminada \\
\hline
\end{tabular}




\begin{tabular}{ccc}
\hline Espécie & r & Fenofase \\
\hline \multirow{2}{*}{ Caesalpinia peltophoroides } & Floração & Botões florais \\
& $-\mathbf{0 , 3 0}$ & Flor. terminada \\
\hline Tipuana tipu & $\mathbf{0 , 3 6}$ & Botões florais \\
\hline & $\mathbf{0 , 4 6}$ & \\
\hline \multirow{2}{*}{ Lagerstroemia indica } & Frutificação & Frutos novos \\
\hline \multirow{2}{*}{ Eugenia uniflora } & $-\mathbf{0 , 5 7}$ & Frutos maduros \\
\hline Caesalpinia peltophoroides & $-\mathbf{0 , 3 6}$ & Frutos novos \\
\hline Tipuana tipu & $\mathbf{- 0 , 4 8}$ & Frutos maduros \\
\hline & $-\mathbf{0 , 5 3}$ & Frutos caindo \\
\hline
\end{tabular}

Quanto ao aspecto positivo da influência da poda sobre a fenofase de árvore desfolhada nas espécies Lagerstroemia indica (Extremosa), $r=0,78$ e Tabebuia chrisotrycha (Ipê-amarelo), $r=0,67$, se deve a ao comportamento de desfolhamento natural dos indivíduos com a época que comumente os moradores da Vila e da Região Sul realizam a poda, ou seja, no inverno.

Porém, para o Ipê-amarelo, a realização da poda nesta fenofase conta com mais uma vantagem, que se refere a eliminação dos folíolos velhos que não apresentam abscisão naturalmente e ficam inseridos na copa como fonte de inóculos para patógenos de manchas foliares como a Apiosphaeria guaranitica (Crosta-marrom).

Dentro das fenofases da mudança foliar, observa-se que as folhas novas são as que se correlacionam negativamente na maioria das espécies: Ipê-amarelo $(r=-0,71)$, Pitangueira $(r=-0,40)$, Sibipiruna $(r=-0,32)$ e Tipuana $(r=-0,42)$, isto devido principalmente ao desequilíbrio gerado pelas podas severas entre copa e sistema radicular. Segundo Seitz (1999), a reação da árvore nestas condições será a de recompor a folhagem original, a partir de gemas epicórmicas, que são responsáveis pela formação de galhos e troncos, e que uma poda severa produz uma profusão de brotos epicórmicos, que causam apenas transtornos, pela constante necessidade de remoção, devido a estes ramos e galhos formados pelas gemas epicórmicas apresentarem uma ligação deficiente com sua base, constituindo um fator de risco futuramente.

Outro fator que pode explicar esta relação negativa entre a fenofase de folhas novas e a poda é pelos danos mecânicos gerados durante a execução desta prática, que ao invés de servir de "renovação" à planta, gera um grande estresse fisiológico à árvore, a qual desloca suas reservas para a formação do calo cicatricial ao invés da formação de folhagem. Isso, tardiamente, pelo lento processo de cicatrização do dano mecânico, servirá como fonte de entrada de fungos apodrecedores, que paulatinamente ampliarão a condição 
de estresse da planta, podendo levar a uma redução gradativa da folhagem e do vigor da planta, até sua morte.

Ferreira (1989) coloca que, em podas muito fortes, a formação de cancros grandes, com tecidos dos calos vigorosos e de pouca flexibilidade, dispostos lateralmente à área do lenho, uma vez invadido por organismos apodrecedores, com a contínua ação do vento, fazem com que o tronco ou galho venha a quebrar no local do cancro.

Umas das conseqüências diretas da realização de uma poda severa durante a fenofase de folhas novas é, obviamente, a redução da folhagem, que no caso da Sibipiruna, reduz seu potencial de produção de sombra e conforto microclimático nas estações mais quentes (primavera e verão), e também causa uma sensível redução na assimilação de carboidratos e reservas para garantir a formação de estruturas reprodutivas.

$\mathrm{Na}$ floração, observou-se que a correlação com a poda foi negativa para todas as fenofases da Extremosa e ocorreu uma correlação negativa fraca com a fenofase de botões florais da Sibipiruna (Caesalpinia peltophoroides), $r=-0,30$. No caso da extremosa, como o objetivo principal na implantação da espécie nas vias urbanas é devido seu belo efeito estético fornecido pela sua abundante floração, recomenda-se podas leves nos exemplares, pois a ação de podas pesadas sobre os tecidos das plantas desta espécie provavelmente induz os tecidos ao estado de juvenilidade, o que, conforme Defavari \& Moraes (2002), consiste em um período que previne a floração até que a planta esteja suficientemente desenvolvida para suprir, com assimilados, o crescimento de estruturas reprodutivas e subseqüente formação de sementes. A transição da planta de um estado juvenil de seus tecidos para madura em uma planta, segundo as autoras, é marcada por diversos aspectos morfológicos, mas em geral estas citam modificações como: diferenças na forma e espessura das folhas, na filotaxia ou hábito de crescimento do ramo, entre outras.

Para o Ipê-amarelo, a poda apresentou-se benéfica na floração, uma vez que todas as suas fenofases apresentam correlações altas, assim como a fenofase de botões florais na Tipuana, tal fato pode estar ligado a uma maior indução dos hormônios responsáveis pela floração, como no caso de várias espécies frutíferas, onde a poda é necessária para uma maior uniformidade na produção, o que vem a caracterizar um dos mais antigos objetivos da realização da poda em árvores.

No caso da influência da poda na fenofase de floração terminada em Sibipiruna, observou-se uma correlação positiva $(r=0,36)$, o que indica que à medida que se aumenta a realização da poda, interfere-se diretamente na duração da floração na espécie, ou seja, como anteriormente mencionado (Tabela 5), o período de floração da Sibipiruna ocorre de Agosto a Novembro, sendo a formação de botões florais concentrada nos meses de Agosto a Outubro. Portanto, a poda esta sendo realizada em período errado, no período de começo da floração, o que mascara o comportamento fenológico da espécie no ambiente urbano. 
Isso leva a dizer que, em caso de necessidade de podas, estas devem ser leves, e preferencialmente nos meses de Junho a Julho, onde não haverá interferência tão acentuada no comportamento fenológico, pois a espécie se encontrará na fenofase de frutos caindo, fase que marca o final do ciclo fenólogico anual da espécie.

Quanto a frutificação, observou-se que a poda tem uma forte correlação negativa com esta, que implica danos à mesma, principalmente em todas as fenofases de frutificação da Pitangueira (Eugenia uniflora), nas fenofases de frutos novos e maduros da Extremosa e de frutos maduros na Tipuana, o que reforça mais uma vez, como citado acima para a floração da Sibipiruna, o fato da técnica da poda estar sendo realizada de forma errônea quanto ao seu período. Isso reforça ainda mais a urgente necessidade de uma campanha de orientação técnica sobre o período correto da realização da poda nas árvores da Vila Santos Dumont.

A única espécie que apresentou correlação positiva com a poda, durante a frutificação, na fenofase de frutos novos $(r=0,33)$, foi a Sibipiruna. Tal fato pode estar relacionado à maior alocação de carboidratos para a formação de frutos, nas inflorescências remanescentes a poda, o que, como anteriormente foi ressaltado, a poda influi sobre o período de duração da floração, onde se observou que, com esta prática, há uma correlação positiva para o aumento de indivíduos com floração terminada.

\section{CONCLUSÕES}

Com o presente estudo conclui-se que:

\section{Para a Extremosa (Lagerstroemia indica)}

- A espécie apresenta o seu período de desfolhamento natural entre maio e setembro (05 meses), sendo este com maior intensidade no mês de agosto;

- A brotação se dá num período de 07 meses, tendo como ápice o mês de setembro;

- A ocorrência de folhas novas e velhas obteve o mesmo tempo de duração (10 meses) tendo seus picos, respectivamente, nos meses de novembro a dezembro, e novembro a dezembro (2003), pela não abscisão natural total das folhas velhas no inverno e de fevereiro a março (2004);

- A formação de botões florais ocorreu de novembro (2003) a abril (2004) e foi retomada em setembro (2004), portanto um período de 06 meses de duração desta fenofase tendo seu pico máximo no mês dezembro;

- A floração adiantada ou da árvore totalmente florida ocorre durante um período de cinco meses, atingindo sua plenitude de floração no mês de fevereiro;

- O término da floração ocorre nos meses de março a abril; 
- Quanto ao efeito da poda, a espécie apresenta um comportamento extremamente sensível à prática em intensidade severa, portanto sendo recomendado apenas podas leves de limpeza para a retirada de ramos ladrões ou mortos.

\section{Para o Ipê-amarelo (Tabebuia chrysotricha)}

- Apresenta um período de desfolhamento natural de 04 meses, que ocorre nos meses de julho a setembro, sendo os demais 03 meses no período de desfolhamento, de dezembro a janeiro, devidos a podas realizadas pelos moradores da Vila;

- A brotação e a fenofase de folhas novas apresentaram um período de igual duração, de onze meses;

- A fenofase de folhas velhas manteve-se presente durante todo período estudo (12 meses), o que revela um fator bastante agravante, quanto à ocorrência desta fenofase, com a possibilidade desta servir como fonte de inóculo ou disseminação da Crosta-marrom (Apiosphaeria guaranitica), doença comum nos exemplares da espécie na arborização da Vila Santos Dumont, o que leva a recomendar a poda dos ramos que apresentem folhas velhas contaminadas pelo fungo;

- A floração da espécie apresenta um ciclo bastante curto, característico da espécie, de apenas 04 meses, nos meses de julho a outubro, que condiz com a espécie em condições de ambiente natural, conforme observada na literatura especializada;

- Assim como a floração, a frutificação também apresentou um curto período de duração, de apenas 03 meses;

- Quanto à poda, o Ipê-amarelo é a espécie que melhor aceita sua prática, sendo até na floração, um fator de indução para sua ocorrência;

\section{Para a Pitangueira (Eugenia uniflora)}

- As fenofases de mudança foliar, floração e frutificação da pitangueira foram as mais longas, sendo encontrados frutos maduros durante todo o período de coleta de dados (12 meses) e a presença de botões florais durante dez meses;

- Durante todo o período também foram encontradas folhas novas e velhas nesta espécie, uma vez que a mesma é semidecídua, perdendo suas folhas ao longo do período e de forma gradativa;

- Os valores encontrados neste trabalho para a floração condizem muito com os valores encontrados para a espécie em ambiente de ocorrência natural (Floresta), o que permite afirmar que é uma espécie rústica, que se adapta muito bem ao ambiente urbano;

- Quanto à poda, a espécie apresenta sérias restrições quanto sua realização no período de frutificação, sendo preferencial a realização apenas de podas leves; 


\section{Para a Sibipiruna (Caesalpinia peltophoroides)}

- As fenofases de mudança foliar apresentaram um comportamento semelhante ao comportamento da pitangueira, quanto à sua duração;

- Tanto a floração quanto à frutificação apresentaram comportamento muito próximo ao relatado na literatura em suas condições de ocorrência natural, podendo concluir-se que a espécie se adapta bem em meio urbano, sendo indicada como espécie adequada para projetos de arborização;

- Para a realização da poda na espécie, deve-se atentar que a mesma não seja realizada durante o período de floração, ocorrida nos meses de agosto a outubro, pois a mesma influi reduzindo o período de ocorrência da floração;

\section{Para a Tipuana (Tipuana tipu)}

- A ocorrência de desfolhamento natural na espécie apresentou um período bastante longo, em torno de 06 meses, mas a observação de tal comportamento fenológico foi prejudicada devida algumas podas esparsas realizadas pelos moradores, no período de estudo;

- As demais fenofases da mudança foliar (brotação, folhas novas e velhas) todas obedeceram a um período de 12 meses;

- Quanto à floração, esta apresenta um período bastante curto, de apenas 02 meses, sendo que o pico de maior intensidade reside nos meses de novembro e dezembro de 2003;

- Na frutificação, observou-se que a maior intensidade de frutos novos é verificada nos meses de dezembro a abril e de frutos maduros ou caindo, nos meses de abril a junho de 2004;

- A prática da poda apresenta tanto aspectos positivos, como no caso da floração onde a poda, assim como no Ipê-amarelo, participa como um indutor floral, para a ocorrência da formação de botões florais, porém a poda age negativamente sobre a formação de folhas novas e na maturação dos frutos, mas tal fato se atribui a falta de conhecimento técnico dos moradores sobre a época correta da prática poda, que por sua vez interfere diretamente no comportamento fenológico dos exemplares, expondo os mesmos a condições permanentes de estresse;

- De âmbito geral entre as espécies, é possível concluir que, espécies como o Ipêamarelo e a Sibipiruna mantêm a grande maioria das fenofases igual àquelas encontradas no ambiente natural. Portanto, estas espécies são aptas para uso em projetos de arborização urbana para fins paisagísticos, pois possuem um comportamento bastante rústico e resistente a intervenções humanas, como a poda; 
- É possível ainda concluir que, em razão do tempo de coleta de dados (12 meses), os resultados obtidos devem ser considerados como preliminares e indicativos da fenologia das espécies estudadas no ambiente urbano, em relação à fenologia presenciada em seu ambiente de ocorrência natural (floresta);

- Recomenda-se ainda, a realização de um programa técnico para orientação dos moradores da Vila Santos Dumont, quanto à época correta da realização da poda em árvores urbanas, sendo esta orientação em forma de um calendário em função do comportamento fenológico das espécies.

\section{REFERÊNCIAS BIBLIOGRÁFICAS}

CARVALHO, R. F. Alguns dados fenológicos de 100 espécies florestais, ornamentais e frutíferas, nativas ou introduzidas na EFLEX de Saltinho, PE. Brasil Florestal, v. 7, n. 25, p. $42-44,1976$.

DEFAVARI, D.; MORAES, L. A. C. Fisiologia da floração. In: CASTRO, P. R. C.; SENA, J. O. A.; KLUGE, R. A. Introdução à fisiologia do desenvolvimento vegetal. Maringá, PR: Eduem, 2002, p. 191-210.

FERREIRA, F. A. Patologia Florestal: Principais doenças florestais no Brasil. Viçosa: Ed. da UFV, 570 p., 1989.

KÖNIG, F. G.; KLEINPAUL, I. S.; FREITAG, A. S.; CECONI, D. E.; CORREA, R. S.; MACHADO, A. A.; KLEINPAUL, J. J.; HECK, D. F.; LONGHI, S. J.; BRUN, E. J. Ocorrência de danos mecânicos nos indivíduos componentes da arborização da Vila Santos Dumont, Santa Maria - RS. In: III SALÃO DE INICIAÇÃO CIENTÍFICA E III MOSTRA CIENTíFICA. Anais... Uruguaiana, RS, 2003a. 2 p.

KÖNIG, F. G.; LONGHI, S.J.; BRUN, E. J.; KLEINPAUL, I. S; FREITAG, A. S.; CECCONI, D. E.; CORREA, R. S.; MACHADO, A. A.; KLEINPAUL, J. J.; HECK, D. F. Composição florística da arborização da Vila Santos Dumont, no Bairro Camobi - Santa Maria, RS. In: 9o CONGRESSO FLORESTAL ESTADUAL DO RIO GRANDE DO SUL. Anais... Nova Prata, RS, 2003b. 8p.

LONGHI, S. J. Fenologia de algumas espécies florestais e ornamentais. Revista Centro de Ciências Rurais. Santa Maria, RS, v. 14, n. 3 - 4. 1984. p. 231 - 240. 
LORENZI, H. Árvores Brasileiras: manual de identificação e cultivo de plantas arbóreas nativas do Brasil. Nova Odessa, SP: Editora Plantarum, v. 1, 1998. 352 p.

MARCHIORI, J. N. C. Dendrologia das angiospermas: leguminosas. Santa Maria,RS: Editora da Universidade Federal de Santa Maria, 1997. 200 p.

MARCHIORI, J. N. C. Elementos de Dendrologia. Santa Maria, RS: Editora da Universidade Federal de Santa Maria, 1995. 163 p.

MARCHIORI, J. N. C.; SOBRAL, M. Dendrologia das angiospermas: Mirtales. Santa Maria,RS: Editora da Universidade Federal de Santa Maria, 1997. 304 p.

MORENO, J. A. Clima do Rio Grande do Sul. Porto Alegre, RS: Secretaria da Agricultura, 1961. $73 \mathrm{p}$.

PREFEITURA MUNICIPAL DE SANTA MARIA. Mapa da cidade de Santa Maria, $22^{\mathrm{a}}$ edição, 2002.

SEITZ, R. A. Poda urbana: princípios básicos e execução. In: I ENCONTRO GAÚCHO DE ARBORIZAÇÃo URBANA. Anais... Pelotas, RS, 1999.

STRECK, E. V.; KÄMPF, N.; DALMOLIN, R. S. D.; KLAMT, E.; NASCIMENTO, P. C.; SCHNEIDER, P. Solos do Rio Grande do Sul. Editora da UFRGS, Porto Alegre. 2002. 107 p.

VELASCO, G. D. N. Arborização viária x sistemas de distribuição de energia elétrica: avaliação dos custos, estudo das podas e levantamento de problemas fitotécnicos. Dissertação (Mestrado em Agronomia) - Escola Superior de Agricultura Luiz de Queiroz. 94 f. Piracicaba, 2003. 